\title{
POLITIK ETIS DAN PENGARUHNYA BAGI LAHIRNYA PERGERAKAN BANGSA INDONESIA
}

\author{
Agus Susilo \\ Pendidikan Sejarah STKIP PGRI Lubuklinggau \\ Agussusilo594@yahoo.co.id \\ Isbandiyah \\ Pendidikan Sejarah STKIP PGRI Lubuklinggau \\ Isbandiyahpris@yahoo.co.id
}

\begin{abstract}
Abstrak
Politik etis dipusatkan membangun irigasi, menyelenggarakan emigrasi, dan memberikan sebuah pendidikan bagi bangsa Indonesia. Politik etis menuntut bangsa Indonesia kearah kemajuan, namun tetap bernaung di bawah penjajahan Belanda. Awal mula dilaksanakan dengan penuh tanggung jawab, bahwa Belanda memperhatikan pribumi dan membantu Indonesia dalam masa kesulitan. Meskipun pada kenyataannya kebijakan politik etis tidak serta merta mensejahterakan rakyat Indonesia, namun mampu merubah tatanan kehidupan bangsa, dimana sistem irigasi ada dimana-mana, masyarakat mengenal sistem pertanian dan perkebunan modern. Emigrasi atau trasmigrasi, dimana masyarakat dikirim keluar pulau Jawa, masyarakat Indonesia menjadi kenal satu sama lain dan membangun hubungan yang baik. Dampak politik etis yang sangat menonjol adalah program edukasi atau pendidikan. Adanya pendidikan bagi bangsa Indonesia, akhirnya dapat merubah pemikiran bangsa Indonesia untuk berfikir lebih maju dan bagaimana memperjuangkan suatu kemerdekaan tanpa jalan perang seperti di masa silam. Keuntungan dibidang pendidikan, yaitu banyak melahirkan tokoh cendikian lokal yang cerdas dan memiliki pemikiran yang setara dengan bangsa barat lainnya. Tokoh Cendikian atau golongan terpelajar bangsa Indonesia inilah yang akhirnya memperjuangkan kemerdekaan rakyat Indonesia dengan semangat nasionalisme dengan cara diplomasi dan perang kemerdekaan Indonesia.
\end{abstract}

Kata Kunci: Politik Etis, Pergerakan, Indonesia

\begin{abstract}
Ethical politics is centered on building irrigation, organizing emigration, and providing education for the Indonesian people. Ethical politics demands the Indonesian nation towards progress, but remains under Dutch colonial rule. The beginning was carried out with full responsibility, that the Dutch took notice of the natives and helped Indonesia in times of adversity. Despite the fact that ethical political policy does not necessarily prosper the people of Indonesia, but is able to change the life of the nation, where irrigation systems are everywhere, people are familiar with modern farming and plantation systems. Emigration or migration, where people are sent out of Java, Indonesian people become acquainted with each other and build good relationships. The very prominent impact of ethical politics is education or education programs. The existence of education for the Indonesian people, finally can change the thinking of the Indonesian people to think more advanced and how to fight for independence without a road to war like in the past. Advantages in the field of education, namely giving birth to many local character figures who are smart and have thoughts that are equivalent to other western nations. This Indonesian character or educated group finally fought for the independence of the Indonesian people in the spirit of nationalism by means of diplomacy and the war of Indonesian independence.
\end{abstract}

Keywords: Ethical Politics, Movement, Indonesia

\section{PENDAHULUAN}

Perkembangan baru dalam politik

Belanda di Indonesia terjadi di Indonesia sekitar awal abad ke-20. Politik baru yang perkembangannya berpedoman pada peningkatan kemajuan rakyat 
Indonesia. Politik baru tersebut disebut dengan ethische politic, yang berarti politik haluan utama (Mulyono, 1968: 99). Menurut Ricklefs, (2007:319). pada permulaan abad ke-20, kebijakan penjajahan Belanda mengalami perubahan arah yang paling mendasar dalam sejarahnya. Kekuasaannya memperoleh definisi kewilayahan baru dengan selesainya upaya-upaya penaklukan yang dilakukan sebelumnya. Kebijakan kolonial Belanda tersebut kini juga memiliki tujuan baru. Politik Etis berakar pada masalah kemanusiaan dan sekaligus pada keuntungan ekonomi. Kecaman-kecaman terhadap pemerintah kolonial Belanda yang dilotarkan dalam novel Max Havelaar (1860) dan dalam dalam berbagai pengungkapan lainnya mulai membuahkan hasil. Semakin banyak suara Belanda yang mendukung pemikiran untuk mengurangi penderitaan rakyat Jawa yang tertindas (Galih, Dhimas Rangga \& Artono, 2017: 752).

Sepanjang abad kesembilan belas, surplus tanah koloni telah diserap setiap tahun sebagai upeti ke kas Belanda. Sebagai berkat pembayaran ini, Belanda dapat memodernisasikan dan membangun masyarakat borjuis yang sukses. Menjelang masa Depresi, Partai Liberal telah menjadi arus dominan dalam pembuatan kebijakan dan politik di Belanda. Periode Politik Etis sebenarnya tergantung pada penaklukan militer dalam waktu yang bersamaan dengan itu, karena hanya ketika Hindia Belanda tergabung ke dalam satu entitas tunggal saja yang memiliki tujuan modernisasi sampai dapat dicapai. Di bawah pemerintahan Gubernur Jenderal van Heutsz jaringan kereta api diperluas di Jawa dan Sumatera, monumen kuno seperti Candi Borobudur dipugar, dan kesempatan pendidikan diperluas selebar-lebarnya (Vickers, Adrian, 2011: 24-27).

Politik Etis berakar pada masalah kemanusiaan dan sekaligus pada keuntungan ekonomi. Di Hindia Timur pada tahun-tahun permulaan abad kedua puluh, orang telah mulai bekerja mengembangkan semangat Politik Etis. Di abad ke-19, sebagian orang Belanda sudah mulai prihatin terhadap kesejahteraan dan status pribumi. Bangsa Indonesia membutuhkan sebuah perubahan kehidupan perekonomian dan pendidikan. Kemauan dari politik etis yang diberikan oleh bangsa Belanda terhadap bangsa Indonesia yang lemah secara adil. Untuk menumbuhkan kesadaran diri dan perasaan individualisme pada elit baru Indonesia yang berpendidikan Barat itu sebenarnya suatu pengurangan terus menerus meningkatkan martabat mereka, yang berakibat pada pengurangan kekuasaan tata pemerintahan pribumi (Van Niel, Robert, 1984: 58).

Van Deventer mendapat inspirasi untuk tulisannya didasarkan atas 
pandangannya terhadap politik penghisapan yang dilakukan oleh bangsa penjajah terhadap masyarakat HindiaBelanda (Indonesia). la menganggap bahwa masyarakat Hindia-Belanda sudah cukup mengalami penderitaan dalam upaya untuk memakmurkan perekonomian negara Belanda. Menurut Van Deventer, sudah saatnya pemerintah Belanda memperhatikan kemajuan rakyat jajahannya. Pemerintah Belanda harus menebus hutangnya kepada masyarakat pribumi dengan memberikan prioritas utama yaitu mensejahterakan mereka (Utomo, 1995: 13). Di awali dengan adanya kesadaran nasional yang pernah dicetuskan oleh R.A. Kartini, karena Kartini telah memasukkan mimpinya nation bewustzjin (kesadaran berbangsa). Oleh karena itu periode Kartini ini lebih tepat disebut "Awal Kesadaran Nasional". Sedangkan berdirinya Budi Utomo dapat disebut "Awal Pergerakan Nasional". Kartini masih bergerak secara individu, sedangkan Budi Utomo bergerak secara organisasi pergerakan nasional. Melalui pergerakan nasional inilah, akhirnya tercapai “Proklamasi Kemerdekaan Indonesia". Proklamasi inilah yang disebut sebagai puncak-puncak pergerakan nasional (Sudiyo, 2002: 17).

Melihat latar belakang dari proses pembetukan sistem politik yag baru, yaitu Politik Etis, maka penulis ingin mengungkapkan bagaimana proses pelaksanaan dari Politik Etis tersebut serta dampak yang ditimbulkan setelah diberlakukannya sistem politik tersebut.

\section{METODE PENELITIAN}

Jenis penilitian ini yaitu penelitian sejarah yang mana metode yang digunakan yaitu metode penelitian sejarah. Metode Sejarah yaitu penelaahan serta sumber-sumber lain yang berisi informasi mengenai masa lampau dan dilaksanakan secara sistematis. Proses penelitian sejarah terdiri penyelidikan, menjelaskan dan memahami kegiatan atau peristiwa yang terjadi beberapa waktu yang lampau untuk menemukan kebenaran. Metode sejarah itu sendiri mempunyai empat langkah yang berurutan: heuristik, kritik, interpretasi, dan historiografi (Gottschalk, 2008 : 39).

Pelaksanaan penelitian dilakukan melalui tahapan sesuai dengan metode penelitian yang digunakan yaitu metode historis. Peneliti mengunakan tahapan penelitian sebagimana yang diungkapkan oleh Sjamsuddin (2007:85-155), yaitu pengumpulan sumber (heuristik), kritik sumber, serta interprestasi dan penulisan sejarah (historiografi).

Heuristik adalah teknik mencari sumber. Berdasarkan bentuk penyajiannya, sumber-sumber sejarah terdiri atas arsip, dokumen, buku, majalah/jurnal, surat kabar, dan lainlain. Saat ini data sejarah bisa di dapat 
dari berbagai macam cara selain studi pustaka, sumber sejarah juga dapat diakses melalui media cetak dan elektronik. Yang terpenting seorang peneliti harus mengetahui bagaimana menangani bukti-bukti sejarah dan bagaimana menghubungkannya (Alian, 2012: 9-10). Agar pencarian sumber berlangsung secara efektif, dua unsur penunjang heuristik harus diperhatikan, yaitu: a) pencarian sumber harus berpedoman pada kerangka kerja, serta memperhatikan permasalahanpermasalahan yang tersirat dalam kerangka tulisan (bab dan subbab), peneliti mengetahui sumber-sumber yang belum ditemukan. b) Dalam mencari sumber di Perpustakaan, peneliti wajib memahami sistem katalog Perpustakaan yang bersangkutan.

Dalam menggunakan sumbersumber sejarah, haruslah mengevaluasi atau melakukan kritik terhadap sumbersumber yang digunakan. Kritik sumber adalah proses menguji sumber, apakah sumber yang dikemukakan asli atau palsu (kritik ekstern) dan apakah dapat dipercaya atau dipertanggung jawabkan atau tidak. Kritik ada dua macam, yaitu: Kritik Ekstern dan Kritik Intern. Kritik ekstern adalah menyelidiki untuk menentukan keaslian dengan menjawab pertanyaan-pertanyaan $5 \mathrm{~W}+1 \mathrm{H}$. Sedangkan kritik intern adalah penentuan dapat tidaknya keterangan dalam dokumen digunakan sebagai fakta sejarah (Yass, 2004: 35-36). Jadi dapat disimpulkan bahwa kritik intern dilakukan untuk mencari keaslian isi sumber atau data guna memperoleh suatu kebenaran atau kekeliruan yang terjadi, sedangkan kritik ekstern bertujuan untuk mencari keaslian sumber yang ditelusuri melalui kritik intern (Alian, 2012: 11).

Interpretasi menyatakan bahwa interpretasi menganalisis data-data sejarah. Dengan interpretasi ini penulis berusaha untuk menghubungkan fakta atau berusaha untuk dapat memberikan penafsiran apa yang ada dalam penulisan laporan penelitian ini. (Kuntowijoyo, 1994: 100). Penafsiran atas fakta harus dilandasi oleh sikap obyektif. Kalaupun dalam hal tertentu bersikap subyektif rasional dan jangan subyektif emosional. Rekontruksi peristiwa sejarah harus menghasilkan sejarah yang benar atau mendekati kebenaran.

Historiografi adalah merangkaikan fakta beserta maknanya secara kronologis/diakronik dan sistematis, menjadi tulisan sejarah sebagai kisah. Kedua sifat uraian itu harus benar-benar terlihat, karena kedua hal itu merupakan bagian dari ciri karya sejarah ilmiah, sekaligus ciri sejarah sebagai ilmu. Historiografi juga suatu perpaduan antara kerja seni (art) dan kemampuan berpikir kritis serta analitis (science) (Gottschalk, 2008 : 39-40). 


\section{PEMBAHASAN}

Proses Pelaksanaan Politik Etis di Indonesia

Pelaksanaan politik etis oleh pemerintah kolonial Belanda, sudah pasti, tidak lepas dari kepentingan kolonial Belanda. Politik etis menuntun bangsa Indonesia kearah kemajuan, namun tetap bernaung di bawah penjajah Belanda. Politik Etis secara resmi ditetapkan pada bulan September 1901, ketika Wilhelmina menyampaikan pidato tahunan. Awal mula dilaksanakan dengan penuh tanggung jawab, bahwa Belanda memperhatikan pribumi dan membantu Indonesia saat mengalami kesulitan. Tidak ada tekad baik dan keikhlasan hati yang tulus untuk melaksanakannya. Mereka berbuat demikian karena takut kritik dan takut kalau tetap membiarkan penderitaan penduduk pribumi terus menerus akan memicu timbulnya perlawanan rakyat secara meluas atau terus menerus. yang kolonialistik-eksploitatis (Daliman, A, 2012: 72).

Pada 17 September 1901 Ratu Belanda, yaitu Ratu Wilhelmina (18901948) mengumumkan mengenai suatu penyelidikan tentang taraf kesejahteraan masyarakat yang berada Jawa. Isi pidato dari Ratu Belanda yaitu "sebagai negara Kristen, Nedherland berkewajiban di Kepulauan Hindia-Belanda untuk lebih memperhatikan penduduk pribumi, memberikan jalan yang tegas terhadap Kristenisasi, serta meresapi keseluruhan tingkah laku pemerintah dengan kesadaran bahwa Netherland mempunyai meringankan beban bangsa Indonesia dengan adanya kebijakan politik etis pada daerah ini. Berhubungan dengan itu, kesejahteraan rakyat Indonesia yang telah mengalami masa penjajahan selama bertahun-tahun. Politik Etis dimulai secara resmi setelah pidato dari Ratu Belanda dan merupakan pertanda bagi dimulainya zaman baru bagi masyarakat Indonesia (Nasution, 1983: 15).

Dalam misi untuk menyelidiki kemerosotan kemakmuran di Jawa, pada tahun 1904 Menteri Idenburg menugaskan Van Deventer dan beberapa rekannya yang juga mendukung jalannya Politik Etis yaitu G.P. Rauffaer, E.B. Kielstra, dan D. Fock untuk membuat sebuah ikhtisar keadaan. Ikhtisar tersebut dibuat dengan menunggu hasil verifikasi penjajahan yang telah menyengsarakan rakyat pada tahun yang sama (1904). Setelah melaksanakan politik pintu terbuka, pemerintah Hindia Belanda memasuki periode kapitalisme modern. Hasil revolusi Industri selama dua puluh tahun sebelumnya terwujud dalam perkembangan industri, perkapalan, perbankan, dan komunikasi yang modern. Laporan tersebut berisi mengenai kemunduran masyarakat Jawa. Laporan yang dibuat Van Deventer 
kemudian memiliki peran yang cukup penting dan kemudian diserahkan kepada pemerintah di Negeri Belanda. Laporan yang dibuat oleh Van Deventer kemudian dijadikan sebagai usulan, namun mendapat tentangan dari kaum Liberal dan Demokrat Radikal. Pengairan, kredit pertanian, dan emigrasi mendapat perhatian, namun tidak dengan pendidikan yang malah diabaikan (Niel, 1984: 58).

Semua ini berlangsung dalam suatu lingkungan ekonomi yang sedang berubah dengan cepat. Aksi-aksi penaklukannya didaerah-daerah diluar Jawa telah memperluas kekuasaan Belanda atas wilayah-wilayah di Nusanntarayang lebih penting dalam pembangunan ekonomi baru dari pada Jawa. Ada dua jenis komoditi yang sangat penting untuk menempatkan Indonesia pada garis depan bagi kepentingan perekonomian dunia pada abad ke-20, yaitu minyak bumi dan karet (Ricklefs, 2007: 320-321).

Pada abad ke-19 sebagian orang Belanda sudah mulai prihatin terhadap kesejahteraan dan status masyarakat pribumi. Mereka kemudian melakukan usaha-usaha secara pribadi untuk perbaikan keadaan. Orang-orang yang berusaha membantu dalam meningkatkan kemakmuran HindiaBelanda yaitu pertama K. E. Holle merupakan seorang yang membantu langsung dalam bidang pertanian kepada orang Sunda dan berusaha untuk memperbaiki keadaan negeri dan penduduk Hindia-Belanda. Kedua, C. Snouck Hurgronje merupakan penasihat yang berhubungan dengan soal-soal pribumi. Beliau merupakan orang yang telah menguasai pengetahuan mengenai kehidupan dan adat kebiasaan penduduk Jawa pada tahun 1890. Beliau juga memberikan konsep tentang memberikan pendidikan, pengairan dan perpindahan penduduk. Untuk pendidikan yang pada awalnya hanya untuk kaum priyayi, namun karena adanya kebutuhan birokrasi yang semakin meningkat, maka banyak anak priyayi rendah dan bahkan orang biasa dapat masuk pendidikan Barat di Hindia-Belanda (Indonesia). Ketiga, W.P.D. de Wolff van Westerrode yang meletakkan dasar-dasar pengorganisaian Bank Kredit untuk Simpan Pinjam dan Pertanian yang mengadakan perlindungan terhadap hutang-hutang (Niel, 1984: 60).

Di bawah Abendanon, politik etis yang memberikan pendidikan bergaya eropa dan pemakaian bahasa Belanda lebih diutamakan. Pada tahun 1900, tiga hoofdensholen Sekolah para kepala yang lama di Bandung, Magelang, dan Probolinggo disusun kembali menjadi Sekolah-Sekolah yang nyata-nyata direncanakan untuk menghasilkan pegawai pemerintah dan diberi nama baru OSVIA (Opleidingscholeh voor inlandsche ambtenaren, Sekolah pelatihan untuk pejabat pribumi). 
Pejabat pribumi di Sekolah di bimbing dan diajari cara melaksanakan kewajiban dalam birokrasi pemerinntahan nantinya. Masa pendidikannya berlangsung 5 untuk menyelesaikan pendidikan di Sekolah rendah Eropa (Galih, Dhimas Rangga \& Artono, 2017: 757).

Penduduk pribumi hanya berkaitan dalam proyek-proyek infrastruktur saja. Dimana mempunyai kaitan lebih langsung dengan kesejahteraan adalah proyekproyek pengairan yang diupayakan pemerintah namun tidak selalu berhasil. Suatu rencana yang akan diupayakan dalam mengalirkan sungai Bengawan Sala harus diabaikan setelah melalui perjalanan panjang padahal telah menelan dana sekitar 17 juta gulden. Meskipun demikian, luas kawasan persawahan yang dapat diairi antara tahun 1885 dan 1930 meningkat sekitar 1,8 kali lipat. Arti pentingnya dapat dilihat pada perspektif jumlah penduduk yang juga meningkat dengan jumlah yang kira-kira sama dalam periode yang sama. Pemerintah kolonial Belanda gagal membuat kebijakan yang dapat mendorong industrialisasi di Indonesia (Ricklefs, 2007: 325-326).

Pemerintah Belanda memegang peranan penting dalam pendidikan. Perubahan pendidikan tidak akan terjadi tanpa adanya persetujuan Gubernur Jenderal atau dewan pendidikan yang bertindak atas nama pemerintah kolonial Belanda. Pendidikan pada masa kolonial
Belanda tidak didasari oleh adanya struktur organisasi yang teratur, sebab pendirian lembaga pendidikan hanya sebagai wujud usaha pemerintah Belanda untuk mempermudahkan dalam pelaksanaan politiknya. Adanya lembaga pendidikan, menjadikan masyarakat berpacu untuk meningkatkan intelektual bangsa, walaupun kebijakan pendidikan masih terbatas (Ismawati, Dwi Nur, dkk, 2017: 284-285).

Agar seseorang atau sekelompok orang yang memiliki kekuasaan sekaligus juga dapat mempunyai kewenangan atas kekuasaan itu, maka yang bersangkutan dapat memperolehnya melalui berbagai sumber kewenangan yang ada. Melalui sumber-sumber kewenangan tersebut yang dimilikinya, dan berbagai macam cara yang dapat ditempuh untuk memperolehnya. Kewenangan atau wewenang dapat diperoleh dari sumbersumber instrumental. Sumber kewenangan ini menunjukkan bahwa hak untuk memerintah berasal dari instrumen yang dimilikinya, seperti keahlian, keterampilan ataupun kekayaan. Adanya seseorang untuk mempunyai kewenangan atau hak untuk memerintah karena dimilikinya keahlian di bidang tertentu ataupun kekayaan yang melimpah (Haryanto, 2005: 13-16).

Banyak sekali usaha yang dijalankan di bidang pendidikan, dan hasil-hasilnya sering kali membuat bangga para pejabat Belanda. Semua 
mendukung politik Etis menyetujui ditingkatkannya dunia pendidikan bagi bangsa Indonesia dan memeratakan kesejahteraan rakyat Indonesia atas Hindia Belanda. Para tokoh Belanda yang mendukung politik etis mengupayakan supaya politik etis terealisasi bagi rakyat Indonesia. Pendekatan elitis diharapkan dapat memberikan sumbangan secara langsung bagi kesejahteraan. Tak satu kebijakan pun dijalankan dengan dana yang cukup memadai, dan tak satu pun menghasilkan apa yang diinginkan oleh para pendukungnya (Ricklefs, 2007:329330).

Pengaruh Politik Etis Terhadap Kebangkitan Nasional

Kebijakan Politik Etis pemerintah Kolonial Belanda dalam mendirikan Sekolah-sekolah bagi anak-anak pribumi merupakan langkah awal dalam perjuangan pemuda di Indonesia. Meskipun sebagian besar yang diperbolehkan sekolah adalah anak-anak dari para bangsawan pribumi (elit pribumi), namun kemudian para anak bangsawan itu muncul sebagai kaum intelek yang memikirkan nasib bangsanya yang tertindas. Para pemuda lulusan sekolah-sekolah tinggi kehakiman, kedokteran dan teknik yang kemudian berperan dalam perjuangan para pemuda Indonesia kalangan terpelajar. Pada awalnya, perjuangan pemuda Indonesia dimulai dari Sekolah Menengah (STOVIA, OSVIA dan sekolah pertanian), namun kemudian mahasiswa dari sekolah tinggi pun ikut mengambil bagian. Lulusan sekolah-sekolah menengah maupun sekolah tinggi itu yang kemudian menjadi pioner dalam perjuangan bangsa Indonesia dan pergerakan emansipasi kemerdekaan (Leirissa, 1985: 29).

Melalui surat kabar dapat dilihat kondisi kaum pribumi pada masa kolonial Belanda, antara lain keterpurukan hidup yang dialami masyarakat Indonesia dalam berbagai bidang, status yang rendah bila dibandingkan dengan golongan Eropa, diskriminasi antara pribumi dan Belanda (Kartodirjo, 2014: 115-116). Melihat keadaan bangsanya yang tertindas demi kepentingan para petinggi dan negara Belanda, para elit pribumi itu kemudian memiliki gagasan dan mengajak rakyat pribumi untuk melawan pemerintahan Kolonial Belanda. Perlawanan tersebut dilatar belakangi atas hasrat ingin maju dan memperluas kesempatan menuntut pendidikan. Gagasan perlawanan atau gagasan untuk mengemansipasi diri tersebut diawali dengan pembentukan organisasi-organisasi pergerakan nasional, seperti Budi Utomo, Serikat Islam, Indische Partij yang kemudian diikuti dengan terbentuknya beberapa organisasi pergerakan nasional lainnya. Di dalam organisasi-organisasi bentukan para elit pribumi tersebut mereka kemudian menyusun siasat-siasat untuk menaikkan derajat bangsa pribumi agar 
tidak lagi tertindas oleh keserakahan pemerintahan Kolonial Belanda.

Organisasi-organisasi Pergerakan Nasional yang dibentuk oleh para generasi muda sebelum tahun 1928, antara lain:

\section{Budi Utomo (20 Mei 1908)}

Budi Utomo lahir dari pertemuanpertemuan dan diskusi yang sering dilakukan di Perpustakaan School tot Opleiding van Inlandsche Artsen oleh beberapa mahasiswa, antara lain Soetomo, Goenawan Mangoenkoesoemo, Goembrek, Saleh, dan Soeleman. Mereka memikirkan nasib bangsa yang sangat buruk dan selalu dianggap bodoh dan tidak bermartabat oleh bangsa lain (Belanda). Istilah Budi Utomo berasal dari kata "Budi" yang barti perangai atau tabiat dan "Utama" yang berarti baik atau luhur. Budi Utomo yang dimaksud oleh pendirinya dalah perkumpulan yang akan mencapau sesuatu berdasarkan keluhuran budi dan kebaikan perangai atau tabiat. Nama Budi Utomo ini terinspirasi dari dialog antara Sutomo dan Dr. Wahidin Sudiro Husodo (Sudiyo, 2002: 21).

Para pendiri organsasi Budi Utomo ini merupakan para murid STOVIA di daerah Kwitang (sekarang termasuk salah satu daerah di Jakarta) yaitu Sutomo, Gunawan, dan Gumbrek pada 20 Mei 1908. Organisasi Budi Utomo didirikann untuk merealisasikan keinginan $\mathrm{Dr}$.
Wahidin Soediro Husodo yang merasa iba melihat nasib bangsanya yang tidak dapat mengenyam pendidikan di bangku sekolah. Beliau bertekad untuk mendirikan studie fonds (dana belajar) atau yang disebut juga dengan beasiswa. Dana tersebut disediakan untuk anakanak Jawa yang tidak dapat melanjutkan pendidikan karena kurangya biaya.

Program utama dari organisasi ini adalah perbaikan pendidikan dan pengajaran bagi anak pribumi. Tujuan Budi Utomo menurut Panyarikan (1993: 20-21) ialah:

a. Mengadakan studie fonds untuk menolong anak-anak Indonesia di tanah Jawa yang akan melanjutkan belajar tetapi tidak memiliki biaya.

b. Mengusahakan supaya bumiputera di tanah Jawa mengetahui adat istiadatnya.

Namun program Budi Utomo pada saat itu masih terbatas di Jawa dan Madura saja. Kemudian berkembang meliputi Bali dan Lombok. Dalam Utomo (1995: 51), tujuan perkumpulan semula adalah mencapai kemakmuran yang harmonis untuk nusa dan bangsa Jawa dan Madura. Usaha-usaha yang akan dilakukan oleh Budi Utomo adalah sebagai berikut, yaitu:

(1) Memajukan pengajaran sesuai dengan yang dicita-citakan Dr. Wahidin. 
(2) Memajukan pertanian, peternakan, dan perdagangan.

(3) Memajukan teknik dan industri, dan

(4) Menghidupkan kembali kebudayaan.

Alasan Budi Utomo juga memusatkan program kemasyarakatan dan kebudayaan karena pada masa itu program edukasi dari Politik Etis Belanda hakikatnya adalah imperialisme kebudayaan secara halus (Kansil \& Julianto, 1985: 23). Maka program Budi Utomo memberikan protes keras bagi penjajahan budaya yang terselubung didalam program edukasi tersebut. Program tersebut bertujuan agar bumiputera mengetahui adat istiadatnya sendiri dan tidak terpengaruh pada kebudayaan Eropa.

\section{Sarekat Islam (10 September 1912)}

Pada tahun 1905 didirikan sebuah organisasi bernama Sarekat Dagang Islami di Jakarta, kemudian pada tahun 1911 Sarekat Dagang Islam di Bogor. Tujuan pendirian Sarekat Dagang Islam antara lain untuk menentang kecurangan pedagang Tionghoa yang menjual bahan dagangan dengan prinsip "menjual barang busuk dengan harga murah". Setelah itu Tirto Adi Suryo berkeliling Jawa hingga sampai di Solo. Di Solo beliau membuka cabang di Solo dengan semboyan "kebebasan ekonomi", rakyat tujuannya, Islam jiwanya. Hal itu adalah untuk kekuatan persatuan dan kesatuan. Perkumpulan yang didirikan di Solo tersebut diketuai oleh $H$. Samanhudi (Hatta, 1997: 9).

Nama Sarekat Dagang Islam kemudian diubah menjadi Sarekat Islam (SI). Pertumbuhan organisasi ini muncul akibat penjajahan Barat yang sangat panjang, sehingga menimbulkan semangat persatuan dam juga disebabkan oleh kesadaran Asia umumnya. Selain itu beberapa sebab khususnya antara lain: (a) perdagangan bangsa Tionghoa menjadi sebuah halangan bagi perdagangan Indonesia, (b) kemajuan gerak langkah penyebaran agama Kristen dan juga ucapan-ucapan yang menghina dalam parlemen Belanda tentang tipisnya kepecayaan agama bangsa Indonesia, dan (c) cara adat lama yang terus digunakan di daerah kerajaankerajaan Jawa semakin lama dirasa tidak sesuai (Pringgodigdo (1977: 4).

\section{Indische Partij (25 Desember 1912)} Indische Partij merupakan organisasi politi pertama di Indonesia yang merupakan pendukung gagasan nasionalisme politik. Penggagas berdirinya Indische Partij adalah E.F.E. Douwes Dekker (Danurdirdjo Setiabudi). Beliau merupakan seorang Indo yang melihat praktik perbedaan ras dan suku bangsa antara bangsa Barat (Belanda dan Eropa) dengan keturunan Indo.

Tujuan pembentukan Indische Partij yaitu nasib kaum Indo yang pada masa itu dianggap sebagai golongan yang 
dilupakan oleh bangsa Belanda. Indische Partij memiliki tujuan "Indie Merdeka" dasarnya adalah Nasionalis Indische, selanjutnya dengan semboyan "Indier untuk Indes" organisasi baru ini berusaha membangun rasa cinta tanah air dari semua "Indiere" dan berusaha mewujudkan kerja sama yang erat untuk kemajuan tanah air dan menyiapkan kemerdekaan. Berdasarkan asas dan tujuan Indische Partij memperjuangkan persatuan nasional. Indische Partij mengemukakan bahwa yang menjadi ikatan adalah perasaan nasional (Irwanto, Dedi, 2007: 33).

Douwes Dekker menyadari bahwa kaum Indo sangatlah sedikit jumlahnya, maka bila beliau tidak melakukan kerjasama, tidak akan mendapat kemenangan. Melalui karangankaranganya dalam majalah de Express, Dekker melakukan propaganda yang berisi: (1) pelaksanaan suatu program “Hindia” buat setiap gerakan politik yang sehat dengan tujuan penghapusan perhubungan kolonial, dan (2) menyadarkan golongan Indo dan penduduk bumiputera bahwa perjuangan yang telah dilakukan bangsa Indonesia akan sia-sia karena suatu ancaman yang sama, yaitu bahaya exploitasi kolonial. Selanjutnya ia menyarankan agar mendirikan sebuah organisasi mampu mengayomi dan mengapresiasi berbagai lapisan masyarakat dan lepas dari batasbatasan yang sempit.
Atas dasar gagasan-gagasan Douwes Dekker, maka dibentuklah sebuah organisasi pergerakan bernama Indische Partij oleh tiga serangkai yaitu Douwes Dekker, Suwardi Suryoningrat, dan Cipto Mangunkusumo. Semboyan dari organisasi ini adalah "Indie untuk Indier". Organisasi ini berusaha membangun nasionalisme pada bangsa Indonesia dan berusaha untuk mewujudkan kerja sama yang baik untuk memperjuangkan hak dan menyiapkan kemerdekaan (Pringgodigdo, 1977: 12).

\section{PENUTUP}

Politik etis berakar pada masalah kemanusiaan dan sekaligus pada keuntungan ekonomi. Pada akhir abad XIX, para pegawai kolonial baru yang datang dari negeri Belanda menuju Indonesia sudah memiliki suatu pemikiran tentang pemerintah kolonial ini. Berbekal pengetahuan dasar dari isi novel Max Havelaar, sebagian besar pegawai kolonial ini membawa pemikiran etis ke Hindia Belanda. Politik etis membawa sedikit perubahan dalam kehidupan bangsa Indonesia. Dimana ada tiga kebijakan baru yang diterapkan, yaitu pendidikan (education), irigasi (pengairan) dan emigrasi (perpindahan penduduk). Bangsa Belanda di negeri Belanda memprotes kebijakan sebelumnya yang tidak memperhatikan kehidupan masyarakat Indonesia. Adanya politik etis ini masyarakat diharapkan 
memiliki hidup yang lebih baik dan makmur.

Politik etis ini ternyata hanya menguntungkan pemerintah Belanda, dimana kebijakan politik etis ini hanya memberikan banyak manfaat bagi bangsa Kolonial Belanda dan bangsa asing lain di Indonesia. Kebijakan politik etis seperti pengairan atau irigasi hanyalah untuk kepentingan perkebunan bangsa Belanda dan bangsa asing lainnya, seperti program trasmigrasi atau perpindahan penduduk dari Jawa ke Sumatera, Kalimantan dan pulau-pulau yang kurang jumlah penduduknya, ternyata hanya untuk perkebunan bangsa Belanda, begitu juga bidang Edukasi atau pendidikan hanya untuk anak-anak keturunan bangsa Belanda, bangsa Eropa dan anak para bangsawan lokal yang mampu menempuh dunia pendidikan. Namun hanya menguntungkan bangsa Belanda dan bangsa asing, ternyata pendidikan banyak melahirkan tokoh cendikian lokal yang cerdas dan memiliki pemikiran yang setara dengan bangsa barat lainnya. Tokoh Cendikian atau pendidikan bangsa Indonesia inilah yang akhirnya memperjuangkan kemerdekaan rakyat Indonesia dengan rasa nasionalisme dan cinta tanah air Indonesia.

\section{DAFTAR PUSTAKA}

Alian, Sair. (2012). Metodologi Sejarah Dan Histiografi. Palembang: Proyek SP4 Universitas Sriwijaya.

Daliman, A, (2012). Sejarah Indonesia Abad XIX-Awal Abad XX. Yograkarta: Ombak.

Galih, Dhimas Rangga \& Artono, (2017). Penerapan Politik Etis di Surabaya Tahun 1911-1930. Avatara Jurnal Pendidikan Sejarah Volume 6, Nomor 3. Fakultas IImu Sosial dan Hukum Unnesa. Surabaya.

Gottschalk, L, (2008). Mengerti Sejarah. Jakarta: Universitas Indonesia.

Haryanto, (2005). Kekuasaan Elit Suatu Bahasan Pengantar. Yogyakarta: JIP Fisipol UGM.

Hatta, M. (1997). Permulaan Pergerakan Nasional. Jakarta: Idayu Press.

Irwanto, Dedi, (2007). Sejarah Indonesia IV. Palembang: FKIP UNSRI.

Ismawati, Dwi Nur, dkk. (2017). The Intelectual's Contribution In The National Movement of In Indonesian 1908-1928. Jurnal Historica Volume 1, Issue. 1. History Education Program Unej. Jember.

Kansil, C.S.T \& Julianto. (1985). Sejarah Perjuangan Pergerakan kebangsaan Indonesia. Jakarta: Erlangga. 
Kartodirjo, S. (2014). Pengantar Sejarah Indonesia Baru: Sejarah Pergerakan Nasional. Yogyakarta: Ombak.

Kuntowijoyo, (1994). Pengantar Ilmu Sejarah. Yogyakarta: Benteng Budaya.

Leirissa, R.Z. (1985). Sejarah Masyarakat Indonesia 1900-1950. Jakarta: Akademika Pressindo.

Mulyono, S. (1968). Nasionalisme Sebagai Modal Perjuangan Bangsa Indonesia I. Jakarta: Balai Pustaka.

Nasution, (1983). Sejarah Pendidikan Indonesia. Bandung: Bumi Aksara.

Niel, R.V. (1984). Munculnya Elit Modern Indonesia. Jakarta: Pustaka Jaya.

Panyarikan, K. S. (1993). Sejarah Indonesia Baru Dari Pergerakan Nasional Samapi Dekrit Presiden. Malang: IKIP Malang.

Pringgodigdo, A.K. (1977). Sejarah Pergerakan Rakyat Indonesia. Jakarta: Dian Rakyat.

Ricklefs, M.C. (2007). Sejarah Indonesia Modern (1200-2004). Jakarta: Serambi Alam Semesta.

Sjamsuddin, Helius. (2007). Metodologi Sejarah. Jakarta: Ombak.

Sudiyo, (2002). Pergerakan Nasional Mencapai \& Mempertahankan Kemerdekaan. Jakarta: Rineka Cipta.
Utomo, C.B. (1995). Dinamika Pergerakan Kebangsaan Indonesia: Dari Kebangkita Hingga Kemerdekaan. Semarang: IKIP Semarang Press.

Vickers, Adrian. (2011). Sejarah Indonesia Modern. Yogyakarta: Insan Madani.

Wiharyanto, A. Kardiyat. Kebijakan Ekonomi Kolonial Tahun 1830-1901. Yogyakarta: FKIP Pendidikan Sejarah Universitas Sanata Dharma. Yass, Marzuki. (2004). Metodologi Sejarah Dan Histiografi. Palembang: Proyek SP4 Universitas Sriwijaya. 
Politik Etis dan Pengaruhnya bagi Lahirnya Pergerakan..., Agus Susilo \& Isbandiyah, 403-416 